\title{
Induction of Acute or Disseminating Bacterial Pneumonia in Mice and Sampling of Infected Organs for Studying the Host Response to Bacterial Pneumonia
}

Wanhai Qin ${ }^{1, ~ *}$, Zhe Liu ${ }^{1}$, Tom van der Poll1, 2 and Alex F. de Vos ${ }^{1}$

\author{
${ }^{1}$ Center of Experimental \& Molecular Medicine, Amsterdam University Medical Centers, location \\ Academic Medical Center, University of Amsterdam, Amsterdam the Netherlands \\ 2Division of Infectious Diseases, Amsterdam University Medical Centers, location Academic Medical \\ Center, University of Amsterdam, Amsterdam the Netherlands \\ *For correspondence: $\underline{\text { w.qin@amsterdamumc.nl }}$
}

\begin{abstract}
[Abstract] Experimental pneumonia models are important tools to study the pathophysiology of lung inflammation caused by microbial infections and the efficacy of (novel) drugs. We have applied a murine model of pneumonia induced by Pseudomonas $(P$.) aeruginosa infection to study acute host antibacterial defense in lungs, and assess epithelial cell specific responses as well as leukocyte recruitment to the alveolar space. To study host responses during disseminating pneumonia, we also applied a model of infecting mice with hypermucoviscous Klebsiella (K.) pneumoniae. In the latter model, K. pneumoniae is restricted to lung during the early phase of infection and at the later time points disseminates to the circulation and distal organs resulting in sepsis. Detailed procedures for induction of pneumonia in mice by Pseudomonas and Klebsiella and for isolation and analysis of infected organs, bronchoalveolar fluid, and bronchial brushes are provided in this article.
\end{abstract}

Keywords: Microbial infection, Acute pneumonia, Disseminating pneumonia, Sepsis, Lung inflammation, $P$. aeruginosa, K. pneumoniae, mouse model

[Background] Epithelial cells and innate immune cells (alveolar macrophages and neutrophils) constitute the first line of defense in the lung against infection (Whitsett and Alenghat, 2015). Pseudomonas (P.) aeruginosa and Klebsiella (K.) pneumoniae are among the most frequent causative bacterial pathogens for hospital-acquired pneumonia, and the latter is a common cause of pneumoniaderived sepsis (Angus and van der Poll, 2013). Both lung epithelial cells and myeloid cells play vital roles in lung immune response against acute airway $P$. aeruginosa infection, partially depending on the bacterial expression of flagellin, and expression of Toll-like receptor 5 on the surface of lung epithelial cells (Kannan et al., 2009; Mijares et al., 2011; Lovewell et al., 2014). We developed Procedure A to evaluate the lung epithelial cell specific and myeloid cell specific role during $P$. aeruginosa infection in mice (Qin et al., 2020). In this model, P. aeruginosa is efficiently cleared from the lung within $24 \mathrm{~h}$ after infection and does not disseminate to other organs (Anas et al., 2016; Qin et al., 2020; Qin et al., 2021a). Considering that pneumonia is one of the leading causes of sepsis, we also utilized a murine model with hypermucoviscous K. pneumoniae (Procedure B), which disseminates from the lung to other organs, and mimics aspects of pneumonia-derived sepsis (de Stoppelaar et al., 2014; Anas et al., 2017; Qin et al., 2021a). In this sepsis model, we evaluate the lung immune defense as well as systemic responses 
by measuring bacterial burden, inflammatory cytokine production, and pathological changes in both lung and distal organs. Procedure $A$ is also applicable to study lung immune responses or inflammation induced by intranasal inoculation of Methicillin-resistant Staphylococcus aureus (Meijer et al., 2021), or bacterial compounds, such as flagellin (Qin et al., 2021b) and lipopolysaccharide (Otto et al., 2020). Procedure B can also be applied to study Streptococcus pneumoniae-evoked pneumonia-derived sepsis (van der Windt et al., 2011; Achouiti et al., 2014; Hommes et al., 2014; van den Boogaard et al., 2018; de Porto et al., 2019).

\section{Materials and Reagents}

1. Eight- to twelve-week-old specific pathogen free (SPF) male and female C57BL6 mice (The Jackson laboratory, Charles River or Harlan) (usually 8 mice per group based on power calculation, see below)

2. Blood agar plates (Biomerieux, catalog number: 1008498740)

3. Silk suture (Mersilk 5-0, Ethicon, catalog number: W580)

4. $1 \mathrm{~mL}$ syringes (BD Plastipak, catalog number: 2102196)

5. $25 \mathrm{G}$ needles (BD Microlance, catalog number: 300600 )

6. $22 \mathrm{G} \mathrm{I.V.} \mathrm{cannula} \mathrm{(ICU} \mathrm{Medical,} \mathrm{catalog} \mathrm{number:} \mathrm{95-201-KY)}$

7. PE50 polyethylene tubing (Becton Dickinson, 7248724)

8. Sandpaper (3M, catalog number: P240)

9. $50 \mathrm{~mL}$ polypropylene tubes (Sarstedt, catalog number: 1040721)

10. $5 \mathrm{~mL}$ polypropylene tubes (Greiner Bio-One, catalog number: 21130132)

11. $1.5 \mathrm{~mL}$ eppendorf tubes (Greiner Bio-One, catalog number: 616201)

12. $2.0 \mathrm{~mL}$ eppendorf tubes (Sarstedt, catalog number: 0084421)

13. Micronic tubes (Micronic, catalog number: MP22400)

14. 96-well U bottom plates (Greiner Bio-One, catalog number: E21023FE)

15. $0.5 \mathrm{~mL}$ heparin minicollect tube (Greiner Bio-One, catalog number: CA20074MH)

16. Bacteria

a. Pseudomonas aeruginosa strains PAK (ATCC-25102; Qin et al., 2021a) and PAO1 (ATCC15692; Anas et al., 2016; Qin et al., 2020), frozen stock in 15\% glycerol with $4 \mathrm{~mm}$ sterile glass beads.

b. Klebsiella pneumoniae serotype 2 (American Type Culture Collection, catalog number: 43816), frozen stock in $15 \%$ glycerol with $4 \mathrm{~mm}$ sterile glass beads.

17. Tryptic soy broth (TSB, Becton Dickinson, catalog number: 211825)

18. Sterile $0.9 \% \mathrm{NaCl}$ (Baxter Healthcare AS, catalog number: 21BO3BB1B)

19. Sterile phosphate-buffered saline (PBS) (Fresenius Kabi, catalog number: 16PK9479)

20. $70 \%$ ethanol (Added Pharma, catalog number: ROL1642610)

21. Isoflurane (Isoflutek, Laboratories Karizoo, catalog number: Reg NL 118938)

22. $10 \%(100 \mathrm{mg} / \mathrm{mL})$ ketamine (Alfasan, catalog number: Reg. NL 5811 UDD) 
23. $0.5 \mathrm{mg} / \mathrm{mL}$ dexmedetomidine (Dexdomitor, catalog number: Reg. NL 10306)

24. 0.5 M EDTA solution (ThermoFisher, catalog number: 15575020)

25. RNaseZap (ThermoFisher, catalog number: AM9780)

26. Pathology cassette (Epredia, catalog number: 22272418)

27. $4 \%$ Formaldehyde (10\% formalin, ProPath)

28. Protease inhibitor cocktail tablets inhibitor (Merck, catalog number: 11836145001)

29. NucleoSpin columns RNA isolation kit (Macherey Nagel, catalog number: 1911/004)

30. MMLV reverse transcriptase (Promega, catalog number: M1705)

31. Cytometric Bead Array (CBA) mouse inflammation kit (BD Biosciences, catalog number: 552364)

32. ELISA kits (R\&D Systems, catalog numbers: DY401 [IL1ß], DY406 [IL6], DY410 [TNF], DY453 [CXCL1], DY443 [CXCL5], DY760 [CCL20], DY3667 [myeloperoxidase], and DY4517 [elastase])

33. Antibodies for flow cytometry

Rat anti-mouse CD11b PE-Cy7 (clone M1/70; BD Biosciences, catalog number:561098)

Rat anti-mouse Siglec-F Alexa Fluor 647 (clone E50-2440; BD Biosciences, catalog number: 562680)

Rat anti-mouse Ly-6C Alexa Fluor 700 (clone AL-21; BD Biosciences, catalog number: 561237)

Rat anti mouse-CD45 PE-eFluor610 (eBiosciences, 30-F11, catalog number: 61-0451-82)

Rat anti-mouse Ly-6G FITC (clone 1A8; Biolegend, catalog number: 127605)

34. Counting beads (Biolegend, catalog number: 424902)

35. Pierce BCA protein assay kit (ThermoFisher, catalog number: 23225)

36. Hematoxylin solution (VWR International, catalog number: VWRK4085.9002)

37. Eosin Y disodium salt (Sigma-Aldrich, catalog number: E6003-25G)

38. Tris base (Merck, catalog number: 11814273001)

39. $\mathrm{MgCl}_{2} \cdot 6 \mathrm{H}_{2} \mathrm{O}$ (Merck, catalog number: 1058330250)

40. Triton X-100 (Merck, catalog number: X100-1L)

41. $32 \% \mathrm{HCl}$ solution (Merck, catalog number: 1003191011)

42. Luria broth (LB, Becton Dickinson, catalog number: 244620)

43. Luria-Bertani (LB) medium (see Recipes)

44. Tryptic Soy Broth (TSB) medium (see Recipes)

45. Ketamine/Dexmedetomidine (see Recipes)

46. $2 \times$ Cell lysis buffer (CLB, see Recipes)

47. 2 mM EDTA-PBS solution (see Recipes)

\section{Equipment}

1. ABSL-2 biosafety cabinet (Biohazard, catalog number: EN12469)

2. Microbiological Incubator (Panasonic, model: MIR-254-PE)

3. Spectrophotometer (Merck, model: Spectrophotometer Pharo 100)

4. Centrifuge (Hettich, model: Riotina 380R) 
5. DNA/RNA UV-cleaner box (Biosan, model: UVT-B-AR)

6. Vortex (VWR International, catalog number:111336624)

7. Anesthesia vaporizer (Datex-Ohmeda, model: Tec7)

8. Microtome (Leica, model: RM2245)

9. Surgical scissors

10. Fine forceps

11. Pipettes (Sartorius, models: $P 20, P 200$ and P1000)

12. Multi-channel pipettes (Sartorius, models: $P 50$ and P300s)

13. Homogenizer (Qiagen, model: 985370-395)

14. $\mathrm{pH}$ meter (Hanna Instruments, catalog number: HI2210-02)

15. L-Shaped disposable spreaders (Thomas Scientific, catalog number: 1202F84)

16. $-80^{\circ} \mathrm{C}$ freezer (Panasonic, catalog number: 13010003 )

17. $-20^{\circ} \mathrm{C}$ freezer (Sanyo, catalog number: alt-314)

18. LightCycler 480 real-time PCR system (Roche, catalog number: D10003)

19. Synergy multi-mode microplate reader (BioTek, catalog number: 232560)

20. Cytoflex S (Beckmann Coulter, catalog number: B75442)

\section{Software}

1. GraphPad Version 8.0 (GraphPad Software)

2. FlowJo software (Becton Dickinson)

3. Power calculation for group size (https://clincalc.com/stats/samplesize.aspx)

\section{Procedure}

Note: Perform all the procedures in a biosafety level 2 laboratory. Moreover, apply aseptic conditions during all procedures.

A. Induction of acute pneumonia by $P$. aeruginosa and sampling of organs

1. Preparation of $P$. aeruginosa inoculum

a. Transfer one glass bead with $P$. aeruginosa PAK bacteria from a frozen stock into a flask with $50 \mathrm{~mL}$ of liquid LB medium and culture at $37^{\circ} \mathrm{C}$ overnight, in a bacterial incubator with agitation at $200 \mathrm{rpm}$.

b. Transfer $1 \mathrm{~mL}$ of the overnight grown bacterial culture into $100 \mathrm{~mL}$ of fresh LB broth. Culture the bacteria at $37^{\circ} \mathrm{C}$ with agitation at $200 \mathrm{rpm}$ for about $3 \mathrm{~h}$. Measure the $\mathrm{OD}_{620 \mathrm{~nm}}$ using a spectrophotometer and place the bacterial culture on ice when the $\mathrm{OD}_{620 \mathrm{~nm}}$ reaches 0.5 .

c. Collect $100 \mathrm{~mL}$ of the bacteria into two $50 \mathrm{~mL}$ tubes and centrifugate at $4,000 \times \mathrm{g}$ for $10 \mathrm{~min}$ at $4^{\circ} \mathrm{C}$, with brake of 5 .

d. Wash bacteria two times with cold sterile $0.9 \%$ saline and resuspend the bacterial pellet in $10 \mathrm{~mL}$ of $0.9 \%$ saline. Adjust the final volume of $0.9 \%$ saline if the $\mathrm{OD}_{620 \mathrm{~nm}}$ was not 0.5 
according to formula: final volume $(\mathrm{mL})=10 \times \mathrm{OD}_{620} / 0.5$.

e. Dilute the bacteria 10 -fold in cold saline to obtain a final concentration of $1 \times 10^{9}$ colonyforming units (CFU)/mL (i.e., $5 \times 10^{6} \mathrm{CFU} / 50 \mu \mathrm{L}$ ). Use the bacteria immediately after preparation, and keep bacteria on ice while transfering to the mice facility.

f. To verify the bacterial concentration of the inoculum, take an aliquot of the inoculum and dilute $10-, 100$ - and 1000 -fold in sterile $0.9 \%$ saline. Plate $50 \mu \mathrm{L}$ of the dilutions on a blood agar (BA) plate using an L-shaped spreader and plate each dilution in triplicate. Culture overnight at $37^{\circ} \mathrm{C}$ and count the colonies on each plate. Calculate the actual bacterial concentration of the inoculum: average CFU of the 10-, 100- or 1,000-fold dilution multiplied by the dilution $=\mathrm{CFU} / 50 \mu \mathrm{L}=\mathrm{CFU} /$ mouse.

g. Other $P$. aeruginosa strains are prepared in a similar manner.

2. Induction of pneumonia (Figure 1A)

a. Anesthetize mice via inhalation of $2-3 \%$ isoflurane (carrier gas $\mathrm{O}_{2}, 2 \mathrm{~L} / \mathrm{min}$ ) for around $2 \mathrm{~min}$. Check if each mouse is properly anesthetized.

b. Flip the mouse onto its back, place it in the palm of left hand and fixate the head gently between thumb and index finger. Hold the mouse at a $45^{\circ}$ angle.

c. Take $50 \mu \mathrm{L}$ of the bacterial suspension with a $100 \mu \mathrm{L}$ pipette. Put the tip close to one of the nostrils of the mouse. Slowly pipette inoculation onto the nostril and wait until the bacterial suspension is completely inhaled.

d. After the liquid is inhaled, put the mouse back in the cage.

e. Check that the mice recover from the procedure after several minutes.

Note: When infection lasts for a short time period (i.e., less than 6 hours), wait for 3 min before infecting the next mouse, and mark all the mice to keep track of the order of mice that were infected. 


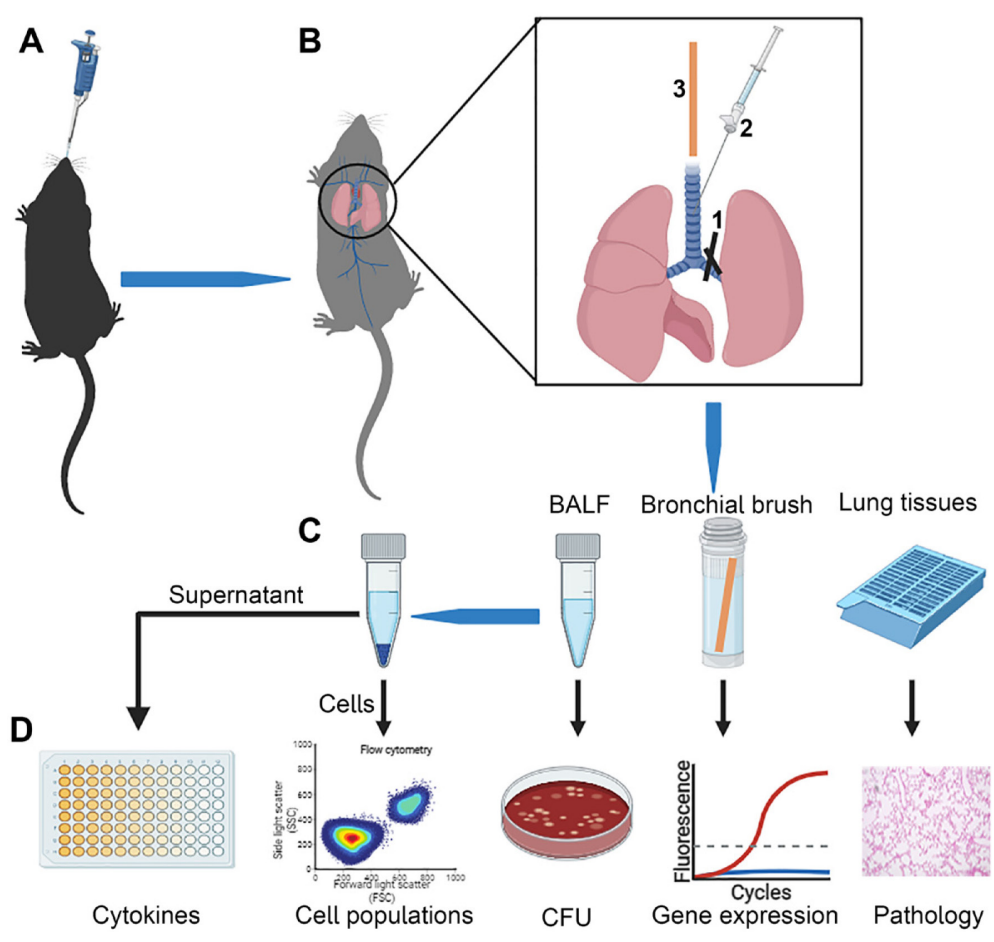

Figure 1. Schematic overview of the procedure for induction of acute pneumonia by $P$. aeruginosa and sampling of organs.

A. Induction of acute pneumonia by infecting mice with 5 million $P$. aeruginosa via the airways. B. Sampling of organs. 1. Put a silk suture around the left bronchus just above the left lung lobe; 2. Collect bronchoalveolar lavage fluid (BALF) using a plastic IV cannula; 3. Perform a bronchial brush with a short roughened PE50 tubing. C-D. Sample processing and measurements. For detailed steps see procedure $\mathrm{A}$.

3. Sampling of organs (Figure 1B)

Note: Perform all the procedure in a bio-safety cabinet. The sampling of all organs from each mouse will take around $3 \mathrm{~min}$. When mice are infected for shorter than $6 \mathrm{~h}$, mice need to be sacrificed in the same order and timing as during inoculation.

a. At 2,6 , or $24 \mathrm{~h}$ after inoculation, mice are anesthetized by intraperitoneal injection with $200 \mu \mathrm{L}$ of ketamine/dexmedetomidine solution.

b. After complete sedation (usually takes about $3 \mathrm{~min}$ ), place the animal on its back on a surgical plate, and spray $70 \%$ ethanol on the neck and belly to disinfect the skin.

c. Collect blood via cardiopuncture using a $1 \mathrm{~mL}$-syringe and $25 \mathrm{G}$ needle.

d. Open the thorax using forceps and scissors to expose the lungs and the trachea.

e. Collect BALF from right lung lobes (Figure 1B1-2)

i. To prevent lavage fluid from entering the left lung lobe, place a silk suture around the left bronchus just above the left lung lobe using a pair of forceps.

ii. Carefully cut a small hole on the upper part of the trachea using a small scissor. Take care not to damage the trachea any further. 
iii. Carefully insert a plastic IV cannula needle (discard the metal inner needle) into the trachea, until the right branch of the airway. Ensure that the catheter is not inserted too far down into the trachea, to keep the integrity of the lung structure.

iv. Stabilize the catheter by tying the trachea around the catheter using a silk suture or with a pair of forceps.

v. Connect a $1 \mathrm{~mL}$ syringe filled with $0.5 \mathrm{~mL}$ of cold and sterile PBS supplemented with $2 \mathrm{mM}$ EDTA to the end of the plastic cannula.

vi. Carefully and slowly inject the solution into the lungs. After $1 \mathrm{~min}$, slowly aspirate the solution while gently massaging the lung.

vii. Collect the liquid in a $2 \mathrm{~mL}$ tube and place on ice.

viii. Repeat Steps $v$ and vii with another $0.5 \mathrm{~mL}$ of PBS-EDTA solution

ix. Pool the two lavage samples together and keep the BALF on ice until further processing.

f. Collect lung brushes (Figure 1B3)

i. Prepare bronchial brushes ahead of organ sampling. Cut PE50 tubing into $3 \mathrm{~cm}$-long pieces. Roughen the surface of the tubing with sandpaper and treat the roughened tubing with RNaseZap. Dry the tubes by placing them in a UV-cleaner box for $30 \mathrm{~min}$.

ii. Insert the short roughened PE50 tubing (bronchial brush) into the right main bronchus with gentle brushing (twisting) and immediately place the bronchial brush in a $2 \mathrm{~mL}$ Eppendorf tube containing $750 \mu \mathrm{L}$ of RA1 buffer from the RNA isolation kit for RNA isolation.

iii. Vortex the tubes thoroughly and place on ice. Transfer to $-80^{\circ} \mathrm{C}$ after returning to the laboratory and store until RNA isolation.

g. Collect the left lung lobe. Carefully harvest the left lung lobe by cutting the left branch of the bronchia with a scissor, and place it in a pathology cassette. Fix the tissue by putting the pathology cassette into a container with freshly prepared $4 \%$ formaldehyde overnight, for histochemical analysis.

h. Mouse cadavers are disposed according to national guidelines for disposal of (genetically modified) mice and pathogens.

4. Sample processing and measurements (Figure 1C and 1D)

a. Evaluation of bacterial burden in alveolar spaces

i. Using a P300 multichannel pipet, fill 64 wells of a 96-well U-bottom plate from columns 1 to 8 with sterile cold PBS (180 $\mu \mathrm{L} /$ well $)$.

ii. Vortex BALF samples and add $20 \mu \mathrm{L}$ of BALF fluid to $180 \mu \mathrm{L}$ of PBS in the first column of the plate for a 10-fold serial dilution. Mix well by pipetting up and down for 10 times. Using a P50 multichannel pipet, transfer $20 \mu \mathrm{L}$ of the first column to the second column containing $180 \mu \mathrm{L}$ of PBS, and repeat the dilution steps up to 8 times.

iii. Using a P50 multichannel pipet, spot $50 \mu \mathrm{L}$ of 4 diluents onto blood agar plates and immediately tilt the plate to a $45^{\circ}$ angle to allow the fluid to flow about $3-4 \mathrm{~cm}$ long. Two plates will be needed for 8 dilutions from one BALF sample. Incubate the plates at $37^{\circ} \mathrm{C}$ 
overnight (or for $14 \mathrm{~h}$ ), and count the colonies.

b. Detection of soluble mediators in the alveolar compartment

i. Transfer $500 \mu \mathrm{L}$ of BALF sample from each mouse to a new $1.5 \mathrm{~mL}$ Eppendorf tube and centrifuge the tube at $400 \times g$ for $8 \mathrm{~min}$ at $4^{\circ} \mathrm{C}$.

ii. Carefully transfer the BALF supernatant using a $1 \mathrm{~mL}$ pipette without touching the cell pellet into a new $1 \mathrm{~mL}$ microtubes, and store the BALF samples at $-20^{\circ} \mathrm{C}$ until use. (See below for processing of the cell pellet).

iii. Inflammatory mediators [cytokines such as interleukin (IL)-1 1 , IL-6, Tumor necrosis factor (TNF)- $\alpha$ and chemokines such as chemokine (C-X-C motif) ligand (CXCL)-1, CXCL-2, CXCL-5, Chemokine (C-C motif) ligand 20], neutrophil degranulation products (myeloperoxidase and elastase) or other soluble mediators in the BALF can be detected by ELISA

iv. Lung damage indictors such as albumin and $\lg M$ in the BALF can be measured by ELISA. Total protein concentration in BALF can be measured by BCA.

c. Detection of leukocyte influx by flow cytometry

i. Resuspend the cell pellet (from Step 4bii) with $1 \mathrm{~mL}$ of cold PBS and centrifuge at $400 \times g$ for $8 \mathrm{~min}$ at $4^{\circ} \mathrm{C}$. Discard the supernatant and repeat this step another time.

ii. Resuspend the cell pellet in $100 \mu \mathrm{L}$ of cold PBS and stain the cells with an antibody cocktail for flow cytometric analysis (e.g., anti-Siglec-F and anti-CD11c for alveolar macrophages, anti-Ly6G and anti-CD11b for neutrophils, or anti-Ly6C and anti-CD11b for monocytes).

iii. After 30 min incubation at $4^{\circ} \mathrm{C}$ in the dark, wash the cells with cold PBS, centrifuge $500 \times g$ for $5 \mathrm{~min}$ at $4^{\circ} \mathrm{C}$, and resuspend in exactly $100 \mu \mathrm{L}$ of PBS. Vigorously vortex the counting beads. Add exactly $10 \mu \mathrm{L}$ of counting beads (10,000 beads) to each sample and mix thoroughly with a multichannel pipette. Analyze cells by flow cytometry. Populations of innate immune cells can be detected based on their surface markers; alveolar macrophages Siglec- $\mathrm{F}^{+} \mathrm{CD} 11 \mathrm{c}^{+}$, neutrophils $\mathrm{Ly}_{6 \mathrm{G}}{ }^{+} \mathrm{CD} 11 \mathrm{~b}^{+}$, and monocytes, either Ly6G-CD11 b+Ly6Chigh or Ly6G-CD11 b+Ly6Clow. Acquire cells and a sufficient number of beads (e.g., 3,000-5,000 beads).

iv. Numbers of total BALF cells and of each of the cell populations can be calculated based on the numbers of counting beads used, and the proportion of cells and beads in the flow cytometric analysis.

d. Detection of gene expression in airway epithelial cells

i. RNA is isolated from bronchial brushes with NucleoSpin columns RNA isolation kit according to the manufacturer's instructions.

ii. cDNA is then synthesized from RNA using MMLV reverse transcriptase according to the manufacturer's instructions.

iii. RT-qPCR is performed for measuring the expression of epithelial cell specific genes (such as coding genes of chemokines and epithelial barrier proteins as described in Qin 
et al., 2021a and 2021b) that are important for lung innate immunity.

e. Pathologic analysis of lung tissues

i. After overnight fixation in formalin, the lung lobe is embedded in paraffin.

ii. Sections of $4 \mu \mathrm{m}$ thickness are cut on a microtome and stained with hematoxylin and eosin according to standard histological procedures (Fischer et al., 2008).

iii. Lung sections are scored by a pathologist blinded for treatment or genotype, as described (Meijer et al., 2021).

B. Induction of disseminating pneumonia by $K$. pneumoniae and sampling of organs

1. Preparation of $K$. pneumoniae inoculum

a. Take one glass bead with $K$. pneumoniae bacteria from a frozen stock and transfer into a flask with $50 \mathrm{~mL}$ of liquid TSB medium. Culture the bacteria at $37^{\circ} \mathrm{C}$ for overnight in a bacterial incubator without shaking.

b. Transfer $1 \mathrm{~mL}$ of the overnight grown bacterial culture into $100 \mathrm{~mL}$ of fresh warm TSB liquid medium. Culture the bacteria at $37^{\circ} \mathrm{C}$ for about $2.5 \mathrm{~h}$ until the $\mathrm{OD}_{620 \mathrm{~nm}}$ reaches 1.0 .

c. Transfer $10 \mathrm{~mL}$ of the bacterial culture into a $50 \mathrm{~mL}$ tubes and add $40 \mathrm{~mL}$ of cold sterile $0.9 \%$ saline. Centrifuge at $4,000 \times g$ for $10 \mathrm{~min}$ at $4^{\circ} \mathrm{C}$, with brake of 0 .

d. Carefully remove the supernatant from the 'loose' bacterial cell pellet. Wash the bacteria twice with cold saline, and resuspend the bacterial pellet with $10 \mathrm{~mL}$ of saline. Adjust the final volume of $0.9 \%$ saline if the $\mathrm{OD}_{620 \mathrm{~nm}}$ was not 1.0 according to the formula: final volume $(\mathrm{mL})=10 \times \mathrm{OD}_{620} / 1.0$.

e. Dilute the bacteria 2,000 times to the final concentration of $200,000 \mathrm{CFU} / \mathrm{mL}$ (i.e., 10,000 $\mathrm{CFU} / 50 \mu \mathrm{L}$ ) in cold saline. Use the bacteria immediately after preparation, and keep bacteria on ice during transfer to the mice facility.

f. To verify the bacterial concentration of the inoculum, take an aliquot of the inoculum, and dilute 10 -, 100 - and 1,000 -fold in sterile $0.9 \%$ saline. Plate $50 \mu \mathrm{L}$ of the dilutions on BA plates in triple and spread bacteria on agar surfaces with a disposable L-shaped spreader. Culture overnight at $37^{\circ} \mathrm{C}$ and count the colonies. Calculate the actual bacterial concentration of the inoculum.

2. Induction of disseminating pneumonia (Figure 2A). The procedure is the same as described above in Step A2. Check for animal discomfort (overall behavior) every $12 \mathrm{~h}$ or more frequently to ensure that discomfort remains within the predefined humane endpoint. 


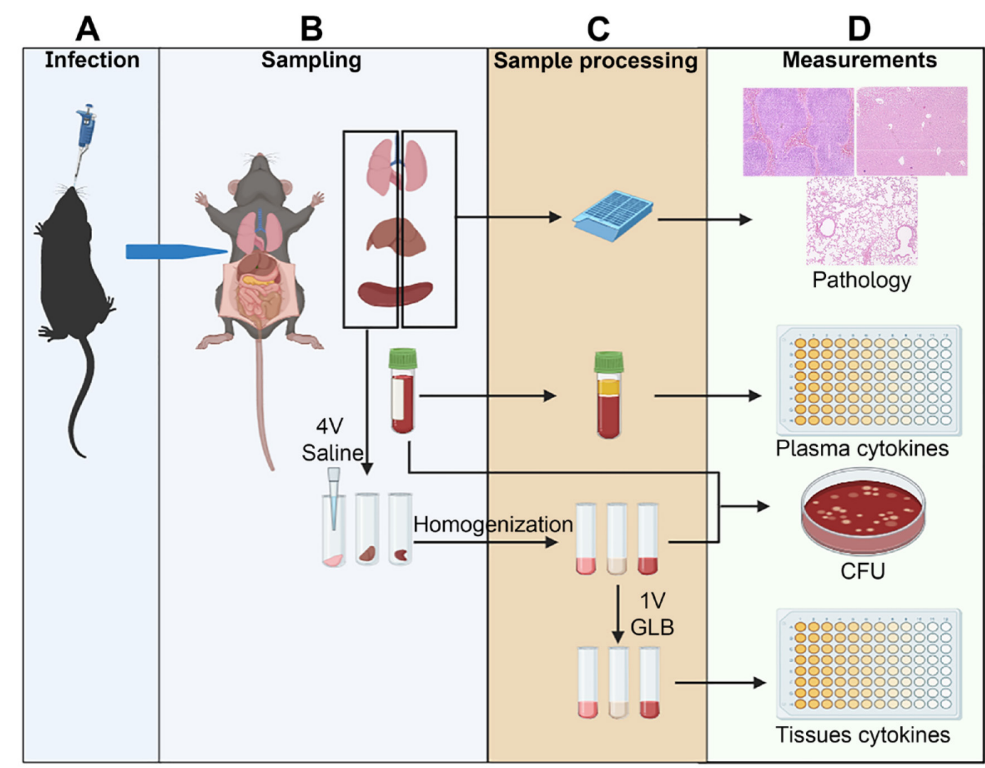

Figure 2. Schematic overview of the procedure for induction of disseminating pneumonia by $K$. pneumoniae and sampling of organs.

A. Induction of pneumonia and pneumonia derived sepsis by infecting mice with 10,000 CFU of K. pneumoniae through the airway. B-C. Sampling and processing of organs (blood, lung, spleen, and liver). D. Measurements (pathological change in lung, liver, and spleen; bacterial burden in blood, lung, liver, and spleen; cytokine and chemokine production in blood, lung, liver, and spleen detected by ELISA). 4V saline: 4 volumes of saline; CLB: Cell lysis buffer.

3. Sampling organs (Figure 2B)

a. At 12,24 , or $42 \mathrm{~h}$ after inoculation, mice are anesthetized by intraperitoneal injection with $200 \mu \mathrm{L}$ of ketamine/dexmedetomidine solution.

b. After complete sedation (usually takes about $3 \mathrm{~min}$ ), place the animal on its back on a surgical plate, and spray $70 \%$ ethanol on the neck and belly to disinfect the skin.

c. Collect blood via cardiopuncture using a $1 \mathrm{~mL}$-syringe and $25 \mathrm{G}$ needle. Transfer $500 \mu \mathrm{L}$ of blood into each heparin coated minicollect tube, gently shake, and place on ice. Around $700 \mu \mathrm{L}$ of blood can be obtained from one mouse.

d. Collect organ tissues:

i. Open the abdomen and thorax using forceps and scissors to expose the lung, the liver, and the spleen.

ii. Collect right lung lobes, half of the spleen, and a small piece of liver; place them separately in three $4 \mathrm{~mL}$ polypropylene tubes, marked on the top with blue (lung), red (spleen), and green (liver) colors respectively, and mouse ID on the side of the tubes.

iii. Weigh the tissues (mg) and add 4 times the weight of cold PBS (in microliters). Verify that organs are on the bottom of the tubes submerged in PBS. Place the tubes on ice.

iv. Collect the left lung lobe, the remaining half of spleen and a small piece of liver and put in a pathology cassette marked with mouse ID. Transfer the pathology cassette into 
container with freshly prepared $4 \%$ formalin for pathologic (histology) analysis later.

v. Alternatively, instead of pathology analysis, BALF and BALF cells can be collected as described above in procedure $A$.

4. Sample processing and measurements (Figure $2 \mathrm{C}$ and 2D)

a. Evaluation of bacterial burden in blood and organs:

i. Homogenate organs with a homogenizer for $10 \mathrm{~s}$ at maximum speed. Immediately place homogenates on ice after the homogenization

ii. Clean the homogenizer after each homogenization by immersion of the tip in $50 \mathrm{~mL}$ tubes with $25 \mathrm{~mL}$ saline, $25 \mathrm{~mL} 70 \%$ alcohol, and $25 \mathrm{~mL}$ saline, respectively. Wash the tip in each solution for $10 \mathrm{~s}$, and dry the homogenizer with tissues after the final wash with saline.

iii. Perform serial dilution of blood and homogenized organs, plating of samples on BA plates and growing of bacterial colonies as described in procedure A, paragraph 4ai-iii.

b. Detection of soluble mediators in plasma and organ homogenates

i. Centrifuge blood samples at $3,000 \times g$ for $10 \mathrm{~min}$ at $4^{\circ} \mathrm{C}$. Carefully, collect the plasma with a $200 \mu \mathrm{L}$ pipette and transfer it to micronic tubes (with mouse ID). Store plasma at $-20^{\circ} \mathrm{C}$ until use.

ii. Dilute organ homogenates with the same volume of $2 \times$ CLB supplemented with protease inhibitor (using the concentration suggested by the manufacturer), vortex vigorously at maximal speed for $5 \mathrm{~s}$, and incubate for $30 \mathrm{~min}$ on ice. Centrifuge the tissue lysates at $3,000 \times \mathrm{g}$, at $4^{\circ} \mathrm{C}$ for $10 \mathrm{~min}$. Carefully collect the supernatants in micronic tubes (labeled with mouse ID), and store at $-20^{\circ} \mathrm{C}$ until analysis

v. Inflammatory mediators (cytokines and chemokines) and neutrophil products (myeloperoxidase and elastase) in the plasma and tissue homogenates can be detected by CBA kit or commercial ELISAs.

vi. Markers of organ damage, including liver damage markers [alanine aminotransferase (ALT) and aspartate transaminase (AST)], kidney damage markers (blood urea and creatinine) and general damage [lactate dehydrogenase (LDH)] in the plasma of mice can be measured by routine clinical chemistry.

c. Pathologic analysis of organs.

i. For paraffin embedding, sectioning and histological staining, see procedure $A$ paragraph $4 \mathrm{e}$ above.

ii. Pathological changes in lung, spleen and liver are scored by a pathologist blinded for treatment or genotype of the mice, as described (Meijer et al., 2021).

\section{Data analysis}

Antibacterial responses in the lung and organs are determined by quantifying bacterial counts in bronchioalveolar lavage fluids (BALF), lung tissues, and organs (Qin et al., 2020 and 2021a); 
Inflammatory response parameters in the lung, such as cytokines levels, are determined by ELISA (using internal standards). Lung inflammation is determined by pathology analysis and by measurement of myeloperoxidase and elastase levels in lung homogenates using ELISA. In BALF, leukocyte influx is determined using flow cytometry (Qin et al., 2020 and 2021a). The epithelial cell responses are evaluated by measuring mRNA levels of inflammatory genes (relative to a housekeeping gene) in lung brushes using RT-qPCR analysis (Qin et al., 2020, 2021a and 2021b). Systemic inflammatory responses are determined by evaluating cytokine levels in plasma and organ homogenates. Organ damage is determined by measurement of ALT, AST, blood urea, creatinine, and LDH concentration in plasma (van Lieshout et al., 2014; de Porto et al., 2019), and by pathology analysis. The statistical differences between two groups (such as uninfected versus infected, or wild type mice versus genetic modified mice) are compared by Mann-Whitney $U$ test.

\section{Recipes}

1. Luria-Bertani (LB) medium

Dissolve $20 \mathrm{~g}$ LB powder in $1 \mathrm{~L}$ of double distilled water.

Autoclave at $121^{\circ} \mathrm{C}$ for $20 \mathrm{~min}$.

Use after cooling down to room temperature or store at $4^{\circ} \mathrm{C}$ for later use.

2. Tryptic Soy Broth (TSB) medium

Dissolve $30 \mathrm{~g}$ TSB powder in $1 \mathrm{~L}$ of double distilled water.

Autoclave at $121^{\circ} \mathrm{C}$ for $20 \mathrm{~min}$.

Use after cooling down to room temperature or store at $4^{\circ} \mathrm{C}$ for later use.

3. Ketamine/dexmedetomidine solution

Add $120 \mu \mathrm{L}$ of $10 \%$ Ketamine solution and $60 \mu \mathrm{L}(0.5 \mathrm{mg} / \mathrm{mL})$ of dexmedetomidine to $820 \mu \mathrm{L}$ of sterile $0.9 \%$ saline, to make a ketamine/dexmedetomidine solution with ketamine $(12.5 \mathrm{mg} / \mathrm{mL})$ and dexmedetomidine $(30 \mu \mathrm{g} / \mathrm{mL})$. Use freshly prepared just before the experiment.

Use $0.2 \mathrm{~mL}$ per mouse.

4. $2 \times$ cell lysis buffer/CLB $(500 \mathrm{~mL})$

$8.77 \mathrm{~g} \mathrm{NaCl}(300 \mathrm{mM})$

$1.82 \mathrm{~g}$ Tris base $(30 \mathrm{mM})$

$0.2 \mathrm{~g} \mathrm{MgCl}_{2} \cdot 6 \mathrm{H}_{2} \mathrm{O}(2 \mathrm{mM})$

$5 \mathrm{~mL}$ of Triton $\mathrm{X}-100(1 \% \mathrm{v} / \mathrm{v})$

Dissolve in $750 \mathrm{~mL}$ of double distilled water.

Adjust $\mathrm{pH}$ to 7.4 using $\mathrm{HCl}$.

Adjust volume to $1,000 \mathrm{~mL}$ with double distilled water.

Store at $4^{\circ} \mathrm{C}$ and use within one month.

Aliquot $25 \mathrm{~mL}$ in a $50 \mathrm{~mL}$ tube and add one tablet of protease inhibitor just before use.

5. 2 mM EDTA-PBS solution

Add $200 \mu \mathrm{L}$ of $0.5 \mathrm{M}$ EDTA solution to $500 \mathrm{~mL}$ of PBS, keep it sterile and store at $4^{\circ} \mathrm{C}$ for up to 
two months.

\section{Acknowledgments}

We acknowledge M.S. ten Brink for helping with the animal experiments. WQ and ZL are supported by the scholarships from China Scholarship Council (CSC). This method is derived from the original publication by Qin et al., 2021a (DOI: 10.1371/journal.ppat.1009491).

\section{Competing interests}

The authors have declared that no competing interests exist.

\section{Ethics}

All experiments were reviewed and approved by the Central Authority for Scientific Procedures on Animals (CCD) and the Animal Welfare Body (IVD) of the Amsterdam-UMC, University of Amsterdam. The animal care and use protocol adhered to the Dutch Experiments on Animals Act (WOD) and European Directive of 22 September 2010 (Directive 2010/63/EU) in addition to the Directive of 6 May 2009 (Directive 2009/41/EC).

\section{$\underline{\text { References }}$}

1. Angus, D. C. and van der Poll, T. (2013). Severe sepsis and septic shock. N Engl J Med 369(9): 840-851.

2. Achouiti, A., Vogl, T., Endeman, H., Mortensen, B. L., Laterre, P. F., Wittebole, X., van Zoelen, M. A., Zhang, Y., Hoogerwerf, J. J., Florquin, S., et al. (2014). Myeloid-related protein-8/14 facilitates bacterial growth during pneumococcal pneumonia. Thorax 69(11): 1034-1042.

3. Anas, A. A., van Lieshout, M. H., Claushuis, T. A., de Vos, A. F., Florquin, S., de Boer, O. J., Hou, B., Van't Veer, C. and van der Poll, T. (2016). Lung epithelial MyD88 drives early pulmonary clearance of Pseudomonas aeruginosa by a flagellin dependent mechanism. $A m \mathrm{~J}$ Physiol Lung Cell Mol Physiol 311(2): L219-228.

4. Anas, A. A., Claushuis, T. A. M., Mohan, R. A., Christoffels, V. M., Aidinis, V., Florquin, S., Van't Veer, C., Hou, B., de Vos, A. F. and van der Poll, T. (2017). Epithelial Myeloid-Differentiation Factor 88 Is Dispensable during Klebsiella Pneumonia. Am J Respir Cell Mol Biol 56(5): 648656.

5. de Stoppelaar, S. F., van 't Veer, C., Claushuis, T. A., Albersen, B. J., Roelofs, J. J. and van der Poll, T. (2014). Thrombocytopenia impairs host defense in gram-negative pneumonia-derived sepsis in mice. Blood 124(25): 3781-3790. 
6. de Porto, A. P., Liu, Z., de Beer, R., Florquin, S., de Boer, O. J., Hendriks, R. W., van der Poll, T. and de Vos, A. F. (2019). Btk inhibitor ibrutinib reduces inflammatory myeloid cell responses in the lung during murine pneumococcal pneumonia. Mol Med 25(1): 3.

7. Fischer, A. H., Jacobson, K. A., Rose, J. and Zeller, R. (2008). Hematoxylin and eosin staining of tissue and cell sections. CSH Protoc 2008:pdb.prot4986.

8. Hommes, T. J., Hoogendijk, A. J., Dessing, M. C., Van't Veer, C., Florquin, S., Colonna, M., de Vos, A. F. and van der Poll, T. (2014). Triggering receptor expressed on myeloid cells-1 (TREM1) improves host defence in pneumococcal pneumonia. J Pathol 233(4): 357-367.

9. Kannan, S., Huang, H., Seeger, D., Audet, A., Chen, Y., Huang, C., Gao, H., Li, S. and Wu, M. (2009). Alveolar epithelial type II cells activate alveolar macrophages and mitigate $P$. aeruginosa infection. PLoS One 4(3): e4891.

10. Lovewell, R. R., Patankar, Y. R. and Berwin, B. (2014). Mechanisms of phagocytosis and host clearance of Pseudomonas aeruginosa. Am J Physiol Lung Cell Mol Physiol 306(7): L591-603.

11. Mijares, L. A., Wangdi, T., Sokol, C., Homer, R., Medzhitov, R. and Kazmierczak, B. I. (2011). Airway epithelial MyD88 restores control of Pseudomonas aeruginosa murine infection via an IL-1-dependent pathway. J Immunol 186(12): 7080-7088.

12. Meijer, M. T., de Vos, A. F., Peters Sengers, H., Scicluna, B. P., Roelofs, J. J., Abou Faycal, C., Uhel, F., Orend, G. and van der Poll, T. (2021). Tenascin C Has a Modest Protective Effect on Acute Lung Pathology during Methicillin-Resistant Staphylococcus aureus-Induced Pneumonia in Mice. Microbiol Spectr: e0020721.

13. Otto, N. A., de Vos, A. F., van Heijst, J. W. J., Roelofs, J. and van der Poll, T. (2020). Myeloid Liver Kinase B1 depletion is associated with a reduction in alveolar macrophage numbers and an impaired host defense during gram-negative pneumonia. $J$ Infect Dis.

14. Qin, W., Brands, X., Van't Veer, C., de Vos, A. F., Scicluna, B. P. and van der Poll, T. (2020). Bronchial Epithelial Tet2 Maintains Epithelial Integrity during Acute Pseudomonas aeruginosa Pneumonia. Infect Immun 89(1): e00603-00620.

15. Qin, W., Brands, X., Van't Veer, C., de Vos, A. F., Sirard, J. C., Roelofs, J. T. H. J., Scicluna, B. $P$ and van der Poll, T. (2021a). Bronchial epithelial DNA methyltransferase 3b dampens pulmonary immune responses during Pseudomonas aeruginosa infection. PLoS Pathog 17(4): e1009491.

16. Qin, W., Brands, X., Van 't Veer C., de Vos, A. F., Scicluna, B. P., van der Poll, T. (2021b). Flagellin induces innate immune genes in bronchial epithelial cells in vivo: Role of TET2. Scand J Immunol 94(1):e13046.

17. van der Windt, G. J., Hoogendijk, A. J., de Vos, A. F., Kerver, M. E., Florquin, S. and van der Poll, T. (2011). The role of CD44 in the acute and resolution phase of the host response during pneumococcal pneumonia. Lab Invest 91(4): 588-597.

18. van Lieshout, M. H., Anas, A. A., Florquin, S., Hou, B., van't Veer, C., de Vos, A. F. and van der Poll, T. (2014). Hematopoietic but not endothelial cell MyD88 contributes to host defense during gram-negative pneumonia derived sepsis. PLoS Pathog 10(9): e1004368. 
19. van den Boogaard, F. E., Brands, X., Duitman, J., de Stoppelaar, S. F., Borensztajn, K. S., Roelofs, J., Hollenberg, M. D., Spek, C. A., Schultz, M. J., van 't Veer, C., et al. (2018). ProteaseActivated Receptor 2 Facilitates Bacterial Dissemination in Pneumococcal Pneumonia. $\mathrm{J}$ Infect Dis 217(9): 1462-1471.

20. Whitsett, J. A. and Alenghat, T. (2015). Respiratory epithelial cells orchestrate pulmonary innate immunity. Nat Immunol 16(1): 27-35. 